\title{
Preparation and Physicochemical Characterization of Topical Niosomal Formulation of Minoxidil and Tretinoin
}

\author{
Khatereh Zarkesh*, Payam Khazaeli, Abbas Pardakhty and Mehdi Rezaifar \\ Faculty of Pharmacy, Kerman University of Medical Sciences, Iran
}

Submission: June 19, 2017; Published: July 03, 2017

*Corresponding author: Khatereh Zarkesh, Faculty of Pharmacy, Kerman University of Medical Sciences, Kerman, Iran, Tel: 07136484117; Email: kh.zarkesh@yahoo.com

\begin{abstract}
Background and aims: Hair loss is a worldwide problem and minoxidil is one of FDA-approved drugs for this stressing condition. Use of topical vesicular formulations containing minoxidil and tretinoin likely increase permeability, efficacy, and release time and decrease the drug toxicity. One of the vesicular systems is the niosome formulation which prepared and investigated about physiochemical properties in this study.

Methods: The niosome formulations containing minoxidil and tretinoin consisting of non-ionic surfactants including sorbitan esters (Span 20,40,60 and 80), polysorbate (Tween 20, 40,60 and 80) with cholesterol were produced by thin layer hydration. Niosome contained $2 \%$ minoxidil and $0.05 \%$ tretinoin was prepared. Niosome properties included microscopic observations, minoxidil and tretinoin release, particle size distribution, percent of confinement and stability during the time were evaluated.

Results: The normal particle size distribution observed in all formulations. All niosomes were like multi-lamellar vesicles except SpanTween 40 formulation. The highest confinement percent of minoxidil was $95 \%$ and $80 \%$ in tretinoin. The minimal changes in particle size were occurred during 6 months in the refrigerator temperature. The $65 \%$ release at $60 \mathrm{~min}$ was seen for niosomes which was higher than minoxidil but lower than tretinoin solutions.

Conclusion: The niosomes were stable and effective during the time due to the presence of mono-oleat chain in the family of Tween and controlled release of minoxidil and tretinoin, respectively. Therefore, niosome formulations containing minoxidil and tretinoin can be used as a new drug delivery system in the treatment of hair loss.
\end{abstract}

Keywords: Hair loss; Drug delivery; Minoxidil; Tretinoin

Abbreviations: AGA: Androgenic Alopecia; DHT: Dihydrotestosterone; AA: Alopecia Areata; MLV: Multi-Lamellar Vesicles; HLB: HydrophilicLipophilic Balance; TPT: Temperature Phase Transition

\section{Introduction}

Skin is one of the most important tissue in the body which protects from other tissues and organs against fluid loss and foreign agents. Also it can play role as absorptive area for topical drug application [1]. Skin has several structural and functional layers included epidermis, derma and hypodermis in which derma contain the hair follicles in all part except palm, red parts of the lips, sole's skin and parts of genital system [2]. Hair cycle has 3 phases included anagen, catagen and telogen. Anagen (growth phase) continued for 2-6years and $85 \%$ of hairs are in this step $[3,4]$. Catagen (transition phase) is the apoptotic step which duration of $1-2$ weeks and $0-5 \%$ of hairs have this step [5]. Finally, $5-10 \%$ of hairs are in telogen step which continued for 3 months and is the rest step [6]. Matrix cells stop proliferating during catagen, and catagen-inducing factors stimulate apoptosis in the hair matrix cells [7].

Hair loss, also called alopecia, means a loss of hair from scalp which is distressing condition and can be classified as androgenic alopecia (AGA) [8], androgenetic alopecia [9], andtelogen effluvium [10] and alopecia areata (AA) [11]. AGA and AA are common forms of hair loss. AGA is caused by the 
heightened sensitivity of scalp follicles to dihydrotestosterone (DHT) whereas AA is induced by autoimmune reactions [12]. There are only two FDA-approved drugs for hail loss which included minoxidil for both genders and finasteride only for men [13]. Minoxidil is a vasodilator which firstly known for its anti-hypertension effect but now it is clear that it stimulates hair growth in AGA [14].

Indeed, hair growing is one of the side effects of this drug by two mechanisms of increasing of blood circulation around the hair follicles and also conversion of testosterone to weaker androgen $[15,16]$. As well as, minoxidil stimulates the activity of cyclooxygenase 1 and prostaglandin E2 production [17]. On the other hand, tretinoin, a retinoic acid derivative, is a mitogen that promotes epidermal cell growth and differentiation, and angiogenesis [18]. Combination of this two drug may be increased the hair growing effects of each alone. Niosomes, are microscopic lamellar structures composed of nonionic surfactants and cholesterol, act as drug reservoirs and the rate of drug release can be modified by changing their composition [19]. Therefore, the physiochemical properties of this vesicular carrier in the action and effect of each drug are highly important. In the present study, a topical niosomal formulation of minoxidil and tretinoin was prepared and their physiochemical properties were evaluated and reported. This paper focuses on the in vitro preparation and evaluation of new niosomal formulation contain minoxidil and tretinoin.

\section{Materials and Methods}

\section{Chemical agents}

Minoxidil powder was purchased from Sepidaj Pharmaceutical Co. (Tehran, Iran). Combination of minoxidil and tretinoin powder was prepared by Smilax Laboratory in order by Iran Darou (Tehran, Iran). Cholesterol, Span 20, 40, 60, 80 and
Tween 20, 40, 60, 80 were purchased from Fluka Chemicals Ltd (Gillingham, England). Chloroform and isopropyl alcohol were purchased from Merck (Germany). All other materials were analytical grades and were available commercially.

\section{Maximum absorbance $\left(\lambda_{\max }\right)$}

Standard concentrations of $2.5,5,7,10$ and $15 \mu \mathrm{g} / \mathrm{ml}$ of tretinoin in ethanol $80 \%$ were prepared. Then their absorptions in wave length range $(200-800 \mathrm{~nm})$ was evaluated using UVvisible spectrophotometer (Shimadzu UV-3100, Japan) against ethanol $80 \%$ as blank. Similar procedure with $0.1 \% \mathrm{HCl}$ as solvent was done for minoxidil. Tretinoin and minoxidil showed the $\lambda_{\max }$ at $339 \mathrm{~nm}$ and $281 \mathrm{~nm}$, respectively. Standard curves were created using different concentrations of minoxidil $(4,8$, $12,16$, and $18 \mu \mathrm{g} / \mathrm{ml}$ in $0.1 \% \mathrm{HCl})$ and tretinoin $(2.5,5,7,10$ and $15 \mu \mathrm{g} / \mathrm{ml}$ in ethanol $80 \%$ ) and evaluation of absorbance at $281 \mathrm{~nm}$ and $339 \mathrm{~nm}$ against $0.1 \% \mathrm{HCl}$ and ethanol $80 \%$ as blanks, respectively.

\section{Preparation of niosomal formulation}

By consideration of $300 \mu \mathrm{mol}$ as total lipid phase of niosomes, stock solution of cholesterol and each surfactant were prepared based on the Table 1. Thin layer hydration of lipid was used for niosome preparation. Briefly, surfactants, cholesterol, minoxidil and tretinoin were dissolved in $5 \mathrm{ml}$ of chloroform, attached to the rotary evaporator device (Heidolph VV2000, Germany) and heated for $25 \mathrm{~min}$ at $60{ }^{\circ} \mathrm{C}$ with $150 \mathrm{rpm}$. In this situation the vacuum pump was turn on to create the thin layer of lipid in the inner wall of the balloon after evaporation of all solvents. Then $5 \mathrm{ml}$ of $60^{\circ} \mathrm{C}$ deionized water was added to this thin layer and hydration was done for $30 \mathrm{~min}$ at $60{ }^{\circ} \mathrm{C}$ with $180 \mathrm{rpm}$ to produce milky like suspensions contained niosomes. Created niosomes were placed in the glass vials and can store at room temperature for $24 \mathrm{hr}$ or at $2-8{ }^{\circ} \mathrm{C}$ for up to 6 months.

Table 1: Cholesterol and Span/Tween ratio in preparation of niosomes.

\begin{tabular}{|c|c|c|c|c|c|c|}
\hline \multirow[b]{2}{*}{ Surfactant type } & \multirow[b]{2}{*}{$\begin{array}{l}\text { Formulation } \\
\text { Number }\end{array}$} & \multicolumn{3}{|c|}{ Surfactant level (ml) } & \multicolumn{2}{|c|}{ Cholesterol level (ml) } \\
\hline & & \%Molar & Span & Tween & $\%$ Molar & Volume \\
\hline \multirow{3}{*}{$\begin{array}{c}\text { Span } 20 \& \text { Tween } \\
20\end{array}$} & F1 & 70 & 0.7 & 1.3 & 30 & 0.7 \\
\hline & F2 & 60 & 0.6 & 1.1 & 40 & 0.9 \\
\hline & F3 & 50 & 0.5 & 0.9 & 50 & 1.2 \\
\hline \multirow{3}{*}{$\begin{array}{c}\text { Span } 40 \text { \& Tween } \\
40\end{array}$} & F4 & 70 & 0.8 & 1.3 & 30 & 0.7 \\
\hline & F5 & 60 & 0.7 & 1.1 & 40 & 0.9 \\
\hline & F6 & 50 & 0.6 & 1 & 50 & 1.2 \\
\hline \multirow{3}{*}{$\begin{array}{c}\text { Span } 60 \& \text { Tween } \\
60\end{array}$} & F7 & 70 & 0.9 & 1.4 & 30 & 0.7 \\
\hline & F8 & 60 & 0.8 & 1.2 & 40 & 0.9 \\
\hline & F9 & 50 & 0.6 & 1 & 50 & 1.2 \\
\hline \multirow{3}{*}{$\begin{array}{c}\text { Span } 80 \text { \& Tween } \\
80\end{array}$} & F10 & 70 & 0.9 & 1.4 & 30 & 0.7 \\
\hline & F11 & 60 & 0.8 & 1.2 & 40 & 0.9 \\
\hline & F12 & 50 & 0.6 & 1 & 50 & 1.2 \\
\hline
\end{tabular}




\section{Niosomal morphology}

Niosome formation, type and shape of niosomes, relative diameter of lipid bilayer wall, particle size, formation of crystals and drops, separation of surfactant and cholesterol and niosome aggregation were evaluated using light microscopy with magnification of $\times 40$.

\section{Analysis of niosomal particle size}

Mean diameter of particular systems were evaluated and chart of particle size distribution was drawn using Malvern Master Sizer 2000E (England). This apparatus can differentiate particles with size between 0.1 to $1000 \mu \mathrm{m}$ and volume mean diameter (d50) was reported.

\section{Physical stability of niosomal suspension}

Niosomal suspensions were placed at $2-8{ }^{\circ} \mathrm{C}$ for one week, 1 , 3 , and 6 months and then niosomal morphology was evaluated using light microscopy and Malvern Master Sizer 2000E.

\section{Confinement percentage of minoxidil and tretinoin}

To evaluate the confinement of drugs in niosomes, the samples were placed in falcon and were centrifuged at $20000 \mathrm{rpm}$. The supernatant which contained unconfined drugs were collected and washed with phosphate buffer and recentrifuged. The precipitations which contained were collected with $1 \mathrm{ml}$ of isopropyl alcohol and their absorbance was assessed at $281 \mathrm{~nm}$ for minoxidil and at $339 \mathrm{~nm}$ for tretinoin against niosome without drug.

\section{In-vitro releasing of minoxidil and tretinoin from niosomes}

Franz Diffusion Cell (Ashk-e-Shishe Co, Tehran, Iran) was used to evaluate the releasing of minoxidil and tretinoin from niosomes in-vitro through an acetate cellulose membrane similar to biological membrane at $37^{\circ} \mathrm{C}$. This glass cell had one donor compound and one receptor chamber with the volume about $15 \mathrm{ml}$. The acetate cellulose membrane was immersed in receptor phases $50: 50 \mathrm{w} / \mathrm{w}$ of water:ethanol $96 \%$ for minoxidil and $80: 20 \mathrm{w} / \mathrm{w}$ of water:ethanol $96 \%$ for tretinoin) for $24 \mathrm{hr}$ and then placed in the related place in cell. Cell was filled completely by receptor phase and a magnet to prevent the existence of any bubbles and provide homogenous distribution of active substance and temperature through the receptor phase. To fix the temperature at $37{ }^{\circ} \mathrm{C}$ around the receptor phase, magnet with mean rate of $300 \mathrm{rpm}$ was used. Sampling from the receptor phase were done at 0 (time of adding $1 \mathrm{ml}$ sample to donor phase), 2, 5, 7, 10, 15, 20, 30, 45, 60 and 90min. the minoxidil and tretinoin contents of each sample were evaluated using UVvisible spectrophotometer.

\section{Results}

Microscopic characteristics of different formulation of niosomes are presented in Table 2 and also selected figures from better formulations are showed in Figure 1. As shown, certain differences were existed in shape, relative number, phase and crystal separations, niosomal aggregation and etc., but most of niosomes were multi-lamellar vesicles (MLV). The F4 formulation was selected as the best formulation due to lack of niosomal aggregation, no crystal separation, lack of particle or droplet of surfactant or minoxidil and tretinoin powders, no phase's separation, and relative high number of niosomes. Changes in particle size distribution in response to storing at 2-8 ${ }^{\circ} \mathrm{C}$ for 1 week, 1,3 , and 6 months are presented in Figure 2. As shown, tretinoin contained niosomes had no changes during the time but minoxidil contained niosome show small changes in particle size especially after 6 months storing.

Table 2: Microscopic characterizations of different formulations of niosomes.

\begin{tabular}{|c|c|c|c|c|c|}
\hline & Surfactants & $\begin{array}{c}\text { \%olar of } \\
\text { Molesterol } \\
\text { Chole }\end{array}$ & Shape & $\begin{array}{c}\text { Numbers } \\
\text { Relative } \\
\text { of } \\
\text { Niosomes }\end{array}$ & $\begin{array}{c}\text { Surfactant } \\
\text { Particle } \\
\text { or Droplet }\end{array}$ \\
\hline \multicolumn{7}{|c|}{ (Span/Tween) } \\
\hline F1 & 20 & 30 & - & 0 & + \\
\hline F2 & 20 & 40 & - & 0 & + \\
\hline F3 & 20 & 50 & - & 0 & + \\
\hline F4 & 40 & 30 & MLVs & High* & + \\
\hline F5 & 40 & 40 & TWV & Low & + \\
\hline F6 & 40 & 50 & TWV & Low & + \\
\hline F7 & 60 & 30 & - & Low & + \\
\hline F8 & 60 & 40 & - & 0 & + \\
\hline F9 & 60 & 50 & - & 0 & + \\
\hline F10 & 80 & 30 & TWV & Low & ++ \\
\hline F11 & 80 & 40 & TWV & Low & ++ \\
\hline F12 & 80 & 50 & - & Low & ++ \\
\hline
\end{tabular}

*High means that the number of niosomes in magnification of $\times 400$ was higher than 50.

MLV, multi-lamellar vesicles; TWV, thin wall vesicle.

Percentage of confinement of minoxidil and tretinoin in niosomes was $95.0 \pm 3.5 \%$ and $80.8 \pm 9.2 \%$, respectively. Percentage of release of minoxidil and tretinoin from niosomes are shown in Figure 3. As presented niosomal formulation had higher percentage of release in comparison to minoxidil solution during $60 \mathrm{~min}$, but had lower percentage of release when compared to tretinoin solution during $20 \mathrm{~min}$.

\section{Discussion}

Although minoxidil is one of the two FDA-approved drugs for androgenic alopecia, but low permeability and solubility limited its application in the treatment of alopecia. Also due to the tendency of the minoxidil to crystallize, its formulation shows relatively inefficient uptake by the skin [20]. On the other hand, topical application of ethanolic based minoxidil has certain adverse effects such as erythema, pruritus, desquamation and 
dryness [21]. It has been reported that tretinoin can be used to increase the ability of minoxidil to penetrate the scalp and this is due to tretinoin-related keratinolytic effect [22]. However, tretinoin is instable in the light and irritates the skin in topical application. Therefore, use of new topical applicable form for two drugs to achieve better outcomes in treatment of alopecia is mandatory.

Previous reports demonstrated that niosome, as a vesicular systems with non-ionic surfactant structure, could be used for increasing the penetration ability of some drugs such as sodium stibogluconate [23], flurbiprofen [24], and capsaicin [25]. Thus, niosomal formulation of tretinoin and minoxidil was prepared and its physicochemical properties were evaluated. We found that one of the formulation which contained $70 \%$ molar surfactant level $(0.8 \mathrm{ml}$ Span 40 and $1.3 \mathrm{ml}$ Tween 40$)$ plus $30 \%$ molar cholesterol $(0.7 \mathrm{ml})$ was the best formulation. This formulation had high number of niosomes with multi-layer wall, lack of surfactant particles or droplets and was stable during the 6 months in $2-8{ }^{\circ} \mathrm{C}$. Finely, it contains well level of minoxidil $(95 \%)$ and tretinoin $(80 \%)$ and also appropriately released it in laboratory conditions.

It has been reported that penetration of niosomal minoxidil in epidermal and dermal layers of skin was greater than dissolved minoxidil in propylene glycol water-ethanol solution [26]. In another study, it was showed that niosomal formulations increased the percentage of drug accumulation in the skin compared with minoxidil hydroalcoholic solution as control and commercial formulations containing 5\% minoxidil and $1 \%$ dexpentanol. Also, physical stability of niosomal formulations for 3 months at refrigerator temperature has shown a fairly high retention of minoxidil inside the vesicles (80\%).

Mixture of surfactants with different hydrophilic-lipophilic balance (HLB) was used for production of niosome. For instance, novel elastic niosomes entrapped with diclofenac diethylammonium with surfactant which had HLB of 3.8-10 was used for evaluation of anti-inflammatory activity [27]. Also when a mixture of surfactant was used, for example Tween 85 , Poloxamer F108 and Tween/Span 60, the total HBL is the mean of all HBL [28]. We used two different surfactant with similar hydrocarbon chain together and all of them could produce niosomes. Based on our previous expertise [29,30], we used sorbitan esters (Span), their ethylinated polyoxan derivatives (Tween) and non-ionic polyoxy ethylene alkyl ether surfactants for preparation of minoxidil and tretinoin niosomes.

When the length of hydrocarbon chain is increased, temperature phase transition (TPT) is also increased. This high TPT can lead to gel status of the lipid bilayer and increased the confinement of water soluble drugs. Among our used surfactants, the Span 60 with HLB 4.7 had the highest TPT. This surfactant was also used in preparation of proniosomes contained piroxicam [31]. A combination of Span 60 with different fatty alcohols in the presence of water and alcohol could produce stable niosomes [32]. Niosomes which were prepared using Span 60 and cholesterol showed high confinement percentage of colchicine [33]. However, recently reported that only Span 20, Span 60 and Tween 20 with cholesterol have ability to produce nano-size vesicle and Span 60 was shown to be a better surfactant for niosomal stability form based on maximum entrapment efficiency and minimal particle size [34].

Drug releasing from new system of drug delivery is dependent to system type, route of administration, nature of confined drug, and type of receptor phase. Confinement and releasing profiles can be changed in response to changes in particle size, multi-layer and fluidity of the membrane which themselves are dependent to length of hydrocarbon chain, its saturation and cholesterol level. In addition, the physicochemical nature of drug can be affect the releasing rate from lipid systems which is reported for insulin and chlorpheniramine [35,36]. Minoxidil is a low water soluble drug and has slow but long time releasing. We found that niosomal system could increase minoxidil permeability and cross- movement through the membrane in comparison to minoxidil solution and may be present similar effect in the invivo systems [37-40].

\section{Conclusion}

Minoxidil and tretinoin are routinely consumed for treatment of alopecia but some limitations are existed in use of them such as low levels of percutaneous penetration and stability. Niosomes are novel drug delivery system which can be used to overcome these limitations [41,42]. In this study, a formulation contain 70\% molar surfactant level (Span/Tween 40) plus 30\% molar cholesterol was created as the best formulation with high number of niosomes in multi-layer wall, without surfactant particles or droplets which was stable over the 6 months in 2-8 ${ }^{\circ} \mathrm{C}$. Also, it had $95 \%$ and $80 \%$ confinement of minoxidil and tretinoin which released it appropriately in comparison to each solution alone. It can be said that niosomal formulation using Span/Tween and cholesterol have potential for the topical delivery of minoxidil/tretinoin in skin diseases such as hail loss albeit after pharmacological and toxicological both at in-vitro and in-vivo levels.

\section{References}

1. Narayanan DL, Saladi RN, Fox JL (2010) Ultraviolet radiation and skin cancer. Int J Dermatol 49(9): 978-986.

2. Sies H, Stahl W (2004) Nutritional protection against skin damage from sunlight. Annu Rev Nutr 24: 173-200.

3. Alonso L, Fuchs E (2006) The hair cycle. J Cell Sci 119(3): 391-393.

4. Rosenquist TA, Martin GR (1996) Fibroblast growth factor signalling in the hair growth cycle: expression of the fibroblast growth factor receptor and ligand genes in the murine hair follicle. Dev Dyn 205(4): 379-386.

5. Tobin DJ, Foitzik K, Reinheckel T, Mecklenburg L, Botchkarev VA, et al. (2002) The lysosomal protease cathepsin L is an important regulator 


\section{Global Journal of Pharmacy \& Pharmaceutical Sciences}

of keratinocyte and melanocyte differentiation during hair follicle morphogenesis and cycling. Am J Pathol 160(5): 1807-1821.

6. Soma T, Tsuji Y, Hibino T (2002) Involvement of Transforming Growth Factor-\& bgr; 2 in Catagen Induction During the Human Hair Cycle. J Invest Dermatol 118(6): 993-997.

7. Dastan M, Najafzadeh N, Abedelahi A, Sarvi M, Niapour A (2016) Human platelet lysate versus minoxidil stimulates hair growth by activating anagen promoting signaling pathways. Biomed Pharmacother 84: 979986

8. Ellis JA, Stebbing M, Harrap SB (2001) Polymorphism of the androgen receptor gene is associated with male pattern baldness. J Invest Dermatol 116(3): 452-455.

9. Ludwig E (1977) Classification of the types of androgenetic alopecia (common baldness) occurring in the female sex. Br J Dermatol 97(3): 247-254.

10. Hadshiew IM, Foitzik K, Arck PC, Paus R (2004) Burden of hair loss: stress and the underestimated psychosocial impact of telogen effluvium and androgenetic alopecia. J Invest Dermatol 123(3): 455457

11. Meidan VM, Touitou E (2001) Treatments for androgenetic alopecia and alopecia areata. Drugs 61(1): 53-69.

12. Herman A, Herman AP (2016) Mechanism of action of herbs and their active constituents used in hair loss treatment. Fitoterapia 114: 18-25.

13. Jimenez JJ, Wikramanayake TC, Bergfeld W, Hordinsky M, Hickman JG, et al. (2014) Efficacy and safety of a low-level laser device in the treatment of male and female pattern hair loss: a multicenter randomized, sham device-controlled, double-blind study. Am J Clin Dermatol 15(2): 115-127.

14. Paus R, Cotsarelis G (1999) The biology of hair follicles. N Engl J Med 341(7): 491-497.

15. Messenger AG, Rundegren J (2004) Minoxidil: mechanisms of action on hair growth. Br J Dermatol 150(2): 186-194.

16. Pardakhty A, Varshosaz J, Rouholamini A (2007) In vitro study of polyoxyethylene alkyl ether niosomes for delivery of insulin. Int J Pharm 328(2): 130-141.

17. Iorizzo M, Tosti A (2015) Treatments options for alopecia. Expert Opin Pharmacother 16(15): 2343-2354.

18. Melkote S, Dhurat RS, Palav A, Jerajani HR (2009) Alopecia in congenital hidrotic ectodermal dysplasia responding to treatment with a combination of topical minoxidil and tretinoin. Int J Dermatol 48(2): 184-185.

19. Hamishehkar H, Rahimpour Y, Kouhsoltani M (2013) Niosomes as a propitious carrier for topical drug delivery. Expert Opin Drug Deliv 10(2): 261-272.

20. Balakrishnan P, Shanmugam S, Lee WS, Lee WM, Kim JO, et al. (2009) Formulation and in-vitro assessment of minoxidil niosomes for enhanced skin delivery. Int J Pharm 377(1-2): 1-8.

21. Williams AC, Barry BW (2012) Penetration enhancers. Adv Drug Deliv Rev 56(5): 603-618.

22. Rogers NE, Avram MR (2008) Medical treatments for male and female pattern hair loss. J Am Acad Dermatol 59(4): 547-566.

23. Williams DM, Carter KC, Baillie AJ (1995) Visceral leishmaniasis in the BALB/c mouse: a comparison of the in vivo activity of five non-ionic surfactant vesicle preparations of sodium stibogluconate. Journal of Drug Targeting 3:1-7.

24. Mokhtar M, Sammour OA, Hammad MA, Megrab NA (2008) Effect of some formulation parameters on flurbiprofen encapsulation and release rates of niosomes prepared from proniosomes. Int J Pharm 361(1-2): 104-111

25. Tavano L, Alfano P, Muzzalupo R, de Cindio B (2011) Niosomes vs microemulsions: new carriers for topical delivery of capsaicin Colloids and Surfaces B: Biointerfaces 87: 333-339.

26. Mura S, Pirot F, Manconi M, Falson F, Fadda AM (2007) Liposomes and niosomes as potential carriers for dermal delivery of minoxidil. J Drug Target 15(2): 101-108.

27. Manosroi A, Jantrawut P, Manosroi J (2008) Anti-inflammatory activity of gel containing novel elastic niosomes entrapped with diclofenac diethylammonium. Int J Pharm 360(1-2): 156-163.

28. Varshosaz J, Pardakhty A, Hajhashemi V, Najafabadi AR (2003) Development and physical characterization of sorbitan monoester niosomes for insulin oral delivery. Drug Deliv 10(4): 251-262.

29. Akbari V, Abedi D, Pardakhty A, Sadeghi-Aliabadi H (2013) Ciprofloxacin nano-niosomes for targeting intracellular infections: an in-vitro evaluation. Journal of Nanoparticle Research 15: 1556

30. Moazeni E, Gilani K, Sotoudegan F, Pardakhty A, Najafabadi AR, et al. (2010) Formulation and in-vitro evaluation of ciprofloxacin containing niosomes for pulmonary delivery. J Microencapsul 27(7): 618-627.

31. Alsarra IA (2009) Evaluation of proniosomes as an alternative strategy to optimize piroxicam transdermal delivery. Journal of Microencapsulation 26(3): 272-278.

32. Bandyopadhyay P, Johnson M (2007) Fatty alcohols or fatty acids as niosomal hybrid carrier: effect on vesicle size, encapsulation efficiency and in-vitro dye release. Colloids and Surfaces B: Biointerfaces 58(2007): 68-71.

33. Hao Y, Zhao F, Li N, Yang Y, Li Ka (2002) Studies on a high encapsulation of colchicine by a niosome system. Int J Pharm 244(1-2): 73-80.

34. Mali N, Darandale S, Vavia P (2013) Niosomes as a vesicular carrier for topical administration of minoxidil: formulation and in-vitro assessment. Drug Deliv Transl Res 3(6): 587-592.

35. Varshosaz J, Pardakhty A, Mohsen S, Baharanchi H (2005) Sorbitan monopalmitate-based proniosomes for transdermal delivery of chlorpheniramine maleate. Drug Delivery 12(2): 75-82.

36. Hadshiew IM, Foitzik K, Arck PC, Paus R (2004) Burden of hair loss: stress and the underestimated psychosocial impact of telogen effluvium and androgenetic alopecia. J Invest Dermatol 123(3): 455457.

37. Hamishehkar H, Rahimpour Y, Kouhsoltani M (2013) Niosomes as a propitious carrier for topical drug delivery. Expert Opin Drug Deliv $10(2): 261-272$

38. Melkote S, Dhurat RS, Palav A, Jerajani HR (2009) Alopecia in congenital hidrotic ectodermal dysplasia responding to treatment with a combination of topical minoxidil and tretinoin. Int J Dermato 48(2): 184-185

39. Mura S, Pirot F, Manconi M, Falson F, Fadda AM (2007) Liposomes and niosomes as potential carriers for dermal delivery of minoxidil. J Drug Target 15(2): 101-108.

40. Paus R, Cotsarelis G (1999) The biology of hair follicles. N Engl J Med 341(7): 491-497

41. Rogers NE, Avram MR (2008) Medical treatments for male and female pattern hair loss. J Am Acad Dermatol 59(4): 547-566.

42. Soma T, Tsuji Y, Hibino T (2002) Involvement of Transforming Growth Factor-\&beta2 in Catagen Induction During the Human Hair Cycle. J Invest Dermatol 118(6): 993-997. 

(C) This work is licensed under Creative

DOI: 10.19080/GJPPS.2017.03.555606
Your next submission with Juniper Publishers will reach you the below assets

- Quality Editorial service

- Swift Peer Review

- Reprints availability

- E-prints Service

- Manuscript Podcast for convenient understanding

- Global attainment for your research

- Manuscript accessibility in different formats ( Pdf, E-pub, Full Text, Audio)

- Unceasing customer service

Track the below URL for one-step submission https://juniperpublishers.com/online-submission.php 